\title{
A Study of Nanoclay Reinforcement of Biocomposites Made by Liquid Composite Molding
}

\author{
Farida Bensadoun, ${ }^{1}$ Nadir Kchit, ${ }^{1}$ Catherine Billotte, ${ }^{1}$ Simon Bickerton, ${ }^{2}$ \\ François Trochu, ${ }^{1}$ and Edu Ruiz ${ }^{1}$ \\ ${ }^{1}$ Department of Mechanical Engineering, Chair on Composites of High Performance (CCHP), Research Centre on Plastics and \\ Composites (CREPEC), Ecole Polytechnique de Montréal, P.O. Box 6079, Station Centre-Ville, Montreal, QC, Canada H3C $3 A 7$ \\ ${ }^{2}$ Centre for Advanced Composite Materials, Department of Engineering, University of Auckland, Private Bag 92019, \\ Auckland 1142, New Zealand
}

Correspondence should be addressed to Edu Ruiz, edu.ruiz@polymtl.ca

Received 1 March 2011; Accepted 3 May 2011

Academic Editor: Susheel Kalia

Copyright ( $\odot 2011$ Farida Bensadoun et al. This is an open access article distributed under the Creative Commons Attribution License, which permits unrestricted use, distribution, and reproduction in any medium, provided the original work is properly cited.

Liquid composite molding (LCM) processes are widely used to manufacture composite parts for the automotive industry. An appropriate selection of the materials and proper optimization of the manufacturing parameters are keys to produce parts with improved mechanical properties. This paper reports on a study of biobased composites reinforced with nanoclay particles. A soy-based unsaturated polyester resin was used as synthetic matrix, and glass and flax fiber fabrics were used as reinforcement. This paper aims to improve mechanical and flammability properties of reinforced composites by introducing nanoclay particles in the unsaturated polyester resin. Four different mixing techniques were investigated to improve the dispersion of nanoclay particles in the bioresin in order to obtain intercalated or exfoliated structures. An experimental study was carried out to define the adequate parameter combinations between vacuum pressure, filling time, and resin viscosity. Two manufacturing methods were investigated and compared: RTM and SCRIMP. Mechanical properties, such as flexural modulus and ultimate strength, were evaluated and compared for conventional glass fiber composites (GFC) and flax fiber biocomposites (GFBiores-C). Finally, smoke density analysis was performed to demonstrate the effects and advantages of using an environment-friendly resin combined with nanoclay particles.

\section{Introduction}

Recent advances in the composites field are related to the addition of nanoparticles such as carbon nanotubes, nanoclays, or silicates nanoparticles to improve the thermal, mechanical, and electrical properties. Nanoparticle additives, like nanoclay, are widely used in various industries such as cable coatings, adhesives, inks, pharmaceutical and automotive $[1,2]$. One of the most common nanoclay forms is montmorillonite (MMT) with a particle thickness of $1 \mathrm{~nm}$ and 70 to $100 \mathrm{~nm}$ crosswise silica platelets $[3,4]$. The choice and extensive use of montmorillonite nanoparticles in previous research is mainly due to the fact that they are commonly available and inexpensive [5]. Minimal content (1-5\% wt) of such additives can improve the reinforcement of the polymer matrix by increasing flexural modulus by up to $31 \%$ and lowering the coefficient of linear thermal expansion [6-8]. However, the incorporation of nanoparticles into the liquid matrix is still a challenge, because it requires proper dispersion and exfoliation of the nanoclay. Since they are hydrophilic in their natural state and unevenly distributed, they must be organically modified to avoid agglomeration between the platelets in the dispersion media $[9,10]$. This modification will increase the degree of exfoliation and thus, increase the level of surface interaction. This can be done through common dispersion techniques such as exfoliationabsorption, in situ polymerization, melt-intercalation, or sonication $[9,11-13]$. Usually, in order to easily incorporate nanoparticles within the matrix, polymer dispersion media are used. The idea is that particle motion would be easier in a less viscous media than the polymer itself. Burgentzle et al. 
[14] studied the behaviour of nanoclays in various solvents to evaluate the interaction between the particles and the dispersion media at different scales. They demonstrated that the surface energy of the dispersion media is superior to clay, which leads to an enhancement of the d-spacing, and therefore a balance between hydrophilic and hydrophobic natures which is the key to good dispersion. The choice of solvent will mainly depend on the matrix. If a media is used to disperse nanoparticles, and is then added to the resin, the quantity control will be crucial, otherwise an overall decrease of mechanical performances may result $[12,15]$. This issue can be overcome for unsaturated polyester (UP) resins since they are composed of 35 to $38 \%$ wt of styrene monomer, which can be easily used as dispersion media without resorting to the use of another solvent.

Liquid composite molding (LCM) is widely used for manufacturing composite parts particularly because it is less expensive compared to autoclave process. LCM processes, such as resin transfer molding (RTM) and vacuum-assisted resin transfer molding (VARTM), are commonly used to manufacture glass fiber composites as well as nanoreinforced composites. Hussain et al. [16], using a resin infusion process, showed a significant improvement in mechanical properties of laminates made of glass fibers using $1 \%$ wt nanoclay. However, the infusion processes listed above are limited by the low viscosity required to impregnate the fibrous reinforcement $[7,12,17]$ and knowing that the viscosity could significantly increase with the addition of nanoclays. Due to their exfoliation, the nanoclay content is often limited to a maximum of 5\%wt. Thus, good knowledge of the matrix rheological behavior is mandatory and the viscosity should be controlled in order to properly impregnate the fibers and produce parts with variability in mechanical performances.

Green technologies are increasingly important on the world stage, and have been implemented in several industries. Bio-based materials appear to have a promising future, and could play an important role in solving current environmental issues. Using these materials could reduce the impact of petroleum based products, and generate lightweight and inexpensive composites. Most often, a bio component is introduced into the conventional resin, offering the significant advantage of reducing fossil fuel dependence for composite manufacturing and contributing to the reduction of greenhouse gas emissions. However, the addition of bio-based content slightly decreases the storage modulus and glass transition temperature $(T g)$, but increases the toughness [18, 19]. Given that stiffness and toughness are opposed performance parameters, a proper balance is then required to obtain an efficient composite by optimizing the percentages of bioproducts and nanoadditives. This can be done by the addition of layered silicates as shown in previous studies [20-22]. The simple replacement of a portion of the resin by a biocomponent reduces the overall mechanical properties, but if used in conjunction with the nanoclay, it counterbalances the properties, because the nanoparticles have greater affinity with bio-based resins $[11,16,17]$.

Nowadays, natural fibers are well known, some proving to be as strong as standard glass fiber. Their use does not require any change in the current methods for composites manufacture [23]. Moreover, natural fibers can also be recycled, which is an added value [24-29]. In terms of mechanical performance, the use of flax fibers shows higher elongation at break than glass fibers, and thermal barrier properties are also improved. Table 1 illustrates the comparative properties of flax and glass fibers [30].

Safety regulations are becoming more restrictive as regards the response of polymers and polymer composites when exposed to fire. The main challenge remains that composite matrices have poor resistance to fire and generate large quantities of smoke, and industry needs to develop costeffective and environmentally friendly flame-retardant systems [9]. Conventional flame retardants, such as ammonium polyphosphate (APP), are well known to be effective in thermoset resins by reducing the peak heat release (PHRR) and the total heat release (THR). However, to improve fire resistance to an acceptable level, very high amounts of APP, close to $30 \% \mathrm{wt}$, are required $[31,32]$. In addition, conventional flame retardants are suspected to be harmful to the environment. This justifies their replacement by nanoclays particles, which have the advantage of acting as an effective flame retardant when mixed at low concentrations in a polymeric matrix [3, 9, 33]. Nazare et al. [9] as well as Gilman et al. [34-36] have shown that incorporating a small amount of nanoparticles ( $1-5 \% \mathrm{wt}$ ) can reduce the PHRR, THR, and fire growth index by $25 \%$. Wilkie [37] also observed that flammability diminution is directly related to the surface treatment used to functionalize the nanoclay and its proportion in the matrix. Thus, it is necessary to optimize the combination between the resin and the type of nanoclay particles. Besides acting like a flame retardant, nanoclays also influence the UP resin cure by reducing cross-linking, which also lowers char formation, thus reducing flammability.

This study will focus on the manufacture of composites by LCM processes using nanocharged resins. Key parameters such as dispersion of nanoparticles will be analyzed thoroughly, as well as the mechanical properties and flammability performance. Two different resins and reinforcements will be considered, where one will lead to the manufacturing of a greener material. Three types of nanoclay particles will be investigated at weight fraction varying from 1 to $5 \%$. The structure of the nanoreinforced thermoset matrices will be studied using rheology, in order to select the best dispersion while keeping in mind the processability of the resin for manufacturing. Glass and flax fiber reinforced composites will be fabricated and mechanically tested to obtain the elastic modulus $(E)$ and the ultimate stress $(\sigma)$. These composites will also be evaluated in terms of their flammability. Mechanical and flammability properties will be explored in this research project to determine and confirm the positive impact of the addition of nanofillers to the manufactured composites.

\section{Experimental}

2.1. Material. In this work, two resins were used to disperse the nanoclays particle and manufacture the composite 
TABLE 1: Comparative mechanical properties of glass and flax fibers [23].

\begin{tabular}{lccccc}
\hline Fiber type & Density $\left(\mathrm{g} / \mathrm{cm}^{3}\right)$ & $\begin{array}{c}\text { Young's modulus } \\
(\mathrm{GPa})\end{array}$ & $\begin{array}{c}\text { Specific modulus } \\
\left(10^{6} \mathrm{~m}^{2} / \mathrm{s}^{2}\right)\end{array}$ & $\begin{array}{c}\text { Elongation at break } \\
(\%)\end{array}$ & $\begin{array}{c}\text { Moisture absorption } \\
(\%)\end{array}$ \\
\hline Glass & 2.55 & 73 & 29 & 3 & - \\
Flax & 1.4 & $60-80$ & $26-46$ & $1.2-1.6$ & 7 \\
\hline
\end{tabular}

TABle 2: Properties of nanoclay particles.

\begin{tabular}{lccc}
\hline & Cloisite 11B & Cloisite 15A & Cloisite 30B \\
\hline D-spacing & $18.4 \AA$ & $31.5 \AA$ & $18.5 \AA$ \\
Density & $1.9-2.1 \mathrm{~g} / \mathrm{cc}$ & $1.66 \mathrm{~g} / \mathrm{cc}$ & $1.98 \mathrm{~g} / \mathrm{cc}$ \\
& Benzy & Bis & \\
Surface & (hydrogenated & (hydrogenated & Alkyl quaternary \\
treatment & tallow alkyl) & tallow alkyl) & ammonium \\
& dimethyl, salts & dimethyl, salt & bentonite \\
& with bentonite & with bentonite & \\
\hline
\end{tabular}

laminates. Petroleum-based unsaturated polyester (R937DPE24) from AOC was initially used to prepare nanoreinforced composites. Then, petroleum-based unsaturated polyester diluted with 8\% of soy oil, Envirez Q11500 INF from Ashland, was used. Both resins were pre-promoted with cobalt ethylhexanoate $(0.05 \%)$ and initiated using methyl ethyl ketone peroxide (MEKP925) from Norox at 1.5 parts per 100 parts of resin. Three different kinds of nanoclay particles were investigated in this work. Table 2 summarizes their properties. They are all montmorillonite-type nanoclays, which is an organically modified layered magnesium aluminum silicate, and are all provided by Southern Clay Products. Two types of fibrous reinforcement were also used in this study, a bidirectional $0^{\circ} / 90^{\circ}$ glass fabric from JB Martin and $0^{\circ} / 90^{\circ}$ flax fibers fabric.

2.2. Nanoclay Dispersion. Dispersion of nanoclay particles into the matrix is key to obtain the desired properties of the composite. In this work, three techniques were used to disperse the nanoparticles in the unsaturated polyester resin: hand mixing, three-roll-mill, and sonication. This paper reports the results obtained with the sonication technique, which proved to lead to the best mixing quality. In this study, a high-frequency ultrasonication bath from Elmasonic was used for nanoparticles dispersion at $35 \mathrm{kHz}$ and $100 \mathrm{~W}$ during an hour. Four different procedures were studied to optimize the ultrasonication parameters and the mixing strategy. Figure 1 shows a flow diagram of the A0 to A4 techniques studied in this work. The dispersion media was either styrene, resin, or a mixture of both. Pure samples were sonicated using technique A0 in order to study the impact of ultrasonication on resin properties and to establish a comparative basis. After sonication, styrene is either removed or added to ensure the same percentage in all samples. Styrene quantity was measured by mass control and incorporated using a high-speed mechanical stirrer.

2.3. Fiber Reinforced Nanocomposite Manufacturing. Two liquid composite molding (LCM) processes were investigated in this research: the Seeman composite resin infusion molding process (SCRIMP), and resin transfer molding process (RTM). The SCRIMP process (see Figure 2) was modified using an aluminum plate on top of the laminate in order to better control the overall thickness of the manufactured composite, and create good surface finish on both sides. Usually, SCRIMP method requires the use of a distribution media, sitting on top of a layer of peel ply, on top of the laminate. In this work, these layers were removed, because of major nanoclays filtration problems. Laminates are composed of either six layers of $0^{\circ} / 90^{\circ}$ woven glass fibers or eight layers of $0^{\circ} / 90^{\circ}$ woven flax and glass fiber fabrics. The infusion pressure was chosen by taking into account the initial viscosity of the nanoreinforced resin and the minimum allowable pressure to prevent boiling and evaporation of styrene. The viscosity of the mixture is critical, because it will influence the filling time of the part and the impregnation of the fiber tows. Manufacture was followed by a 2 -hour postcure at a $100^{\circ} \mathrm{C}$. This step was preceded by a 3-hour post-cure at room temperature for SCRIMP composite plates only.

During the SCRIMP infusion process, the thickness of the part varies from the resin inlet to the vent location. This is due to the pressure gradient during resin flow and the decompaction of the fibers. After filling, the pressure in the cavity becomes uniform and the thickness equilibrates. However, this step, called postfilling, is very slow and often the resin cures before reaching the thickness equilibrium. To avoid this phenomenon, the filling time has to be relatively short compared to the post-filling stage [38]. Furthermore, if the resin flow is too fast, voids can be entrapped within the laminate reducing its mechanical performance. It has been demonstrated in previous work [39] that macro and micro voids are formed at, respectively, low and high capillary number. Since in this study resin viscosity will be affected by the presence of nanoparticles, then the pressure gradient in the mold has to be adjusted to ensure the same flow velocity (i.e., capillary number) for manufacture of all composite samples. To improve the robustness of the process, several composites plates were manufactured by SCRIMP using a polyester resin with different viscosities. The viscosity of the resin was modified by styrene dilution. At the same time, the vacuum pressure was varied for each laminate according to the viscosity of the applied resin. Figure 3(a) shows the resulting infusion times as a function of vacuum pressure. This evolution is found to be linear and can be illustrated by the model of the following (1) in terms of vacuum pressure, resin viscosity and infusion time:

$$
\frac{t}{\mu}=-\frac{a}{P}+b \quad \text { or } \quad P=\frac{a}{b-t} \mu,
$$




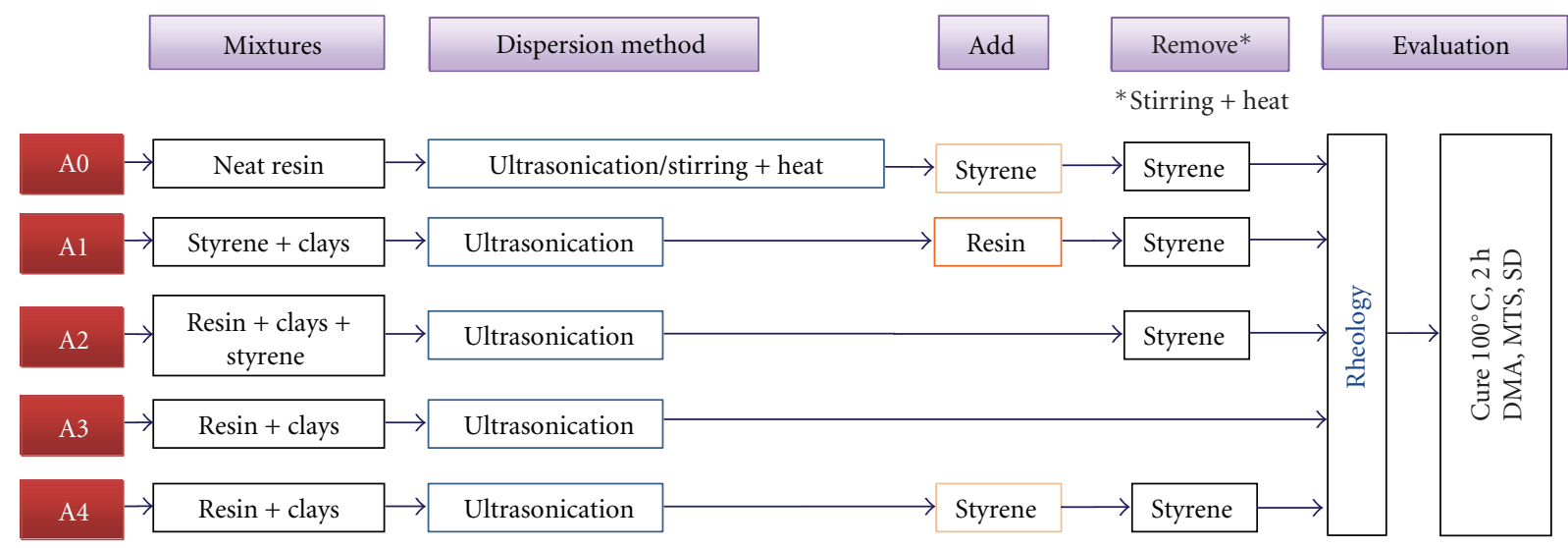

Figure 1: Nanoclay dispersion methods.

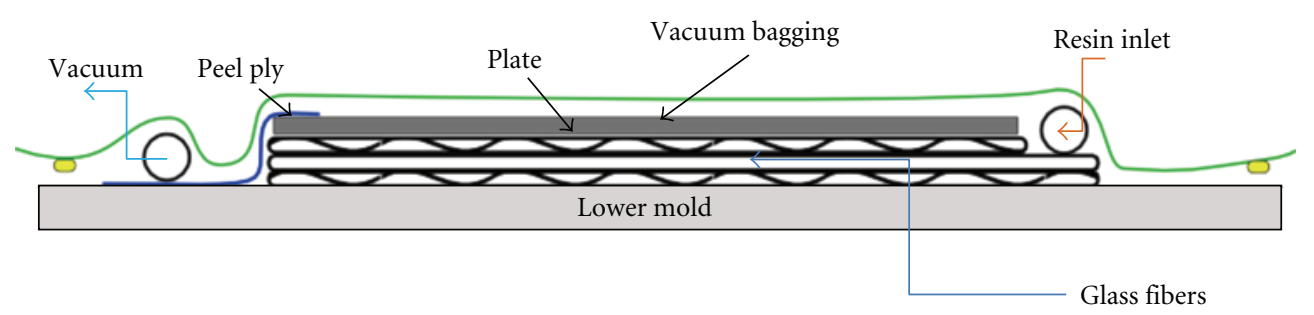

FIGURE 2: SCRIMP composite manufacturing setup. The liquid resin infusion was performed throug a classical VARTM process. The aluminum plate on top reduce thickness variation of the part. The reinforcement is a combination of oriented fibers and mat.

where $t$ is the infusion time in minutes, $P$ the vacuum pressure in $\mathrm{kPa}, \mu$ the viscosity of the resin in $\mathrm{Pa} \cdot \mathrm{s}$, and $a$ and $b$ are experimental parameters (resp., 928.7 and 3.18). In this work, the viscosity of the nanocharged resin will vary according to the nanoclay content. It is desirable to keep a constant capillary number for all samples. To do so, the infusion time has to be similar for all manufactured plates. Since the composite plates have a fixed length of $65 \mathrm{~cm}$ and the same reinforcement, by fixing a desired filling time, the vacuum pressure can be adjusted according to the viscosity of the resin. Figure 3(b) shows the experimental results for an infusion time of $6 \mathrm{~min} 20 \mathrm{sec}$ with different resin viscosities. For this mold configuration and a fixed filling time, the previous model is used to adjust the vacuum pressure $P$ as a function of nanocharged resin viscosity.

In addition to the SCRIMP process, an RTM manufacturing process was also implemented in this research. As shown in Figure 4, the fibers were placed between the two rigid aluminum mold parts and were clamped with a hydraulic press. The advantage of this process is that the thickness of the laminates is controlled by the mold cavity. A plate, used as a spacer, was added to adjust the depth of this cavity in order to obtain the same dimensions for both processes. Afterwards, the RTM setup was heated up to reduce the viscosity of the resin and improve impregnation of the fibers. Table 3 summarizes the manufacturing parameters used during SCRIMP and RTM experiments.

2.4. Material Characterization. Simple shear rheology tests were performed on the nanodispersed resins using a con- trolled stress rheometer MRC501 from Anton Paar with concentric cylinders and parallel plate geometries. Tensile and flexural mechanical tests were performed using a mechanical testing and simulation (MTS) machine from Lab Integration. A crosshead speed of $1.15 \mathrm{~mm} / \mathrm{min}$ and a span length of $60 \mathrm{~mm}$ were used according to ASTM D790 standard. For all tests, a minimum of four samples were tested to ensure reproducibility. The flammability of the samples was studied by testing smoke density according to ASTM D2843. For this test, the flame strikes the sample at an angle of 45 degrees for a period of 4 minutes. Above the sample holder, a lamp and a light detector are located on each side of the chamber to measure the light transmission. The light intensity decreases with the smoke density generated by the burning sample. In other to obtain reproducible results, six samples of the same size were tested.

\section{Nanoclay Dispersion and Processability Analyses}

3.1. Nanoclay Dispersion Analysis. In this work, rheology was used to study the dispersion of the nanoclays in the liquid resin. The objective was to link the shear viscosity behavior to the level of dispersion and exfoliation of the nanoclay platelets in the mixture. Higher shear viscosity is associated with a better exfoliation of the structure $[40,41]$. The shear viscosity can also be related to the ability of the polymer to bond to the nanoclays and will depend on the type of clay and its surface treatment. 


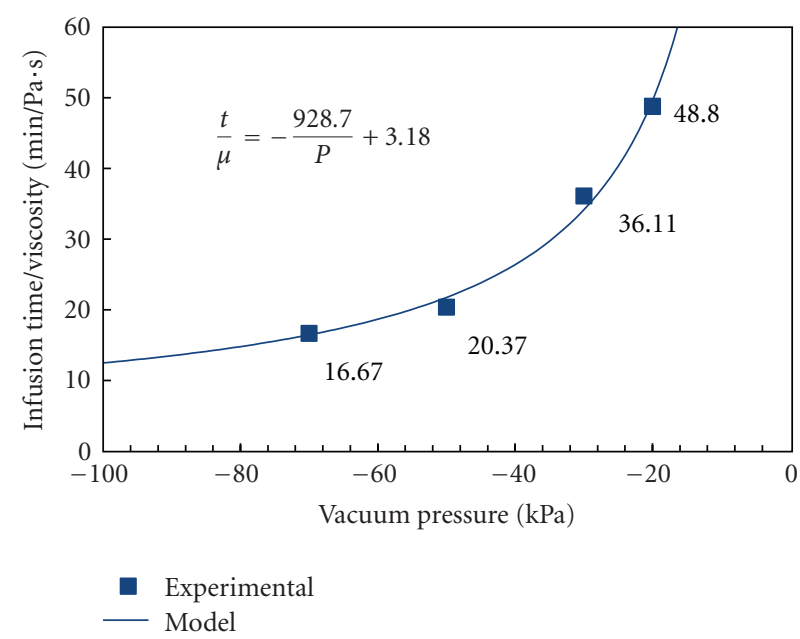

(a)

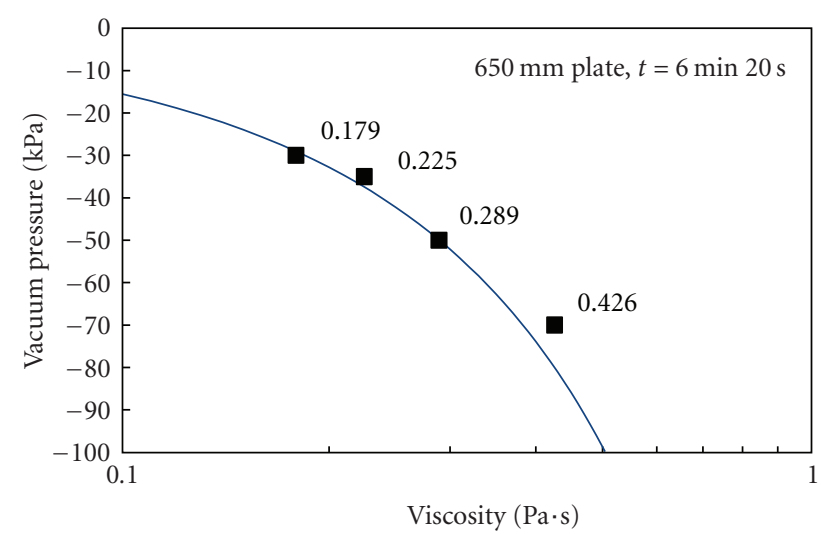

- Experimental viscosity

- Model

(b)

FIGURE 3: Optimization of SCRIMP process parameters (a) infusion time and (b) vacuum pressure required to obtain the same filling time.

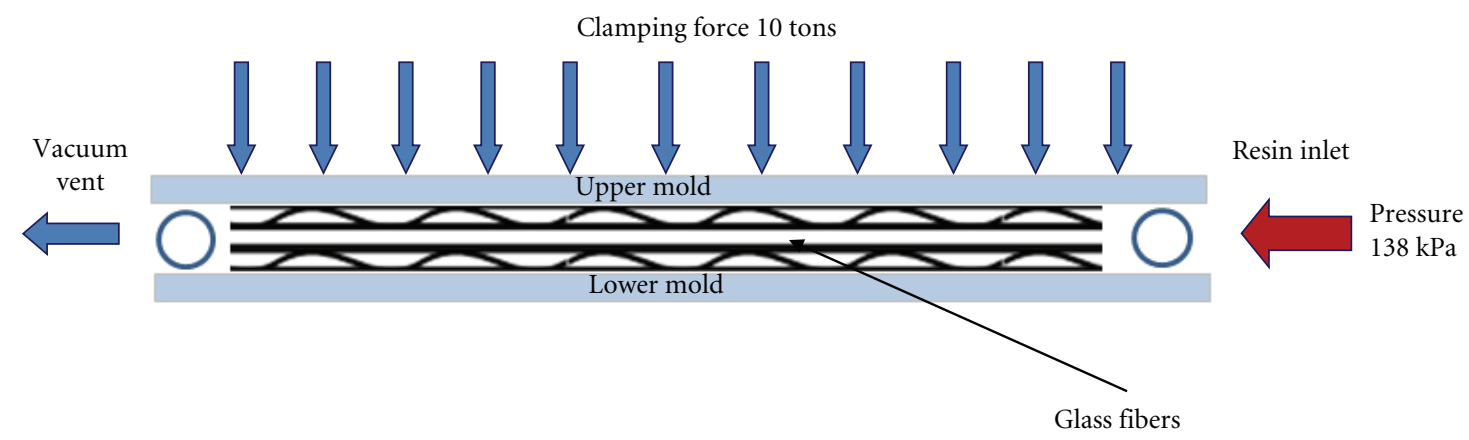

FIGURE 4: RTM composite manufacturing setup.

Shear experiments were carried out on resin-nanoclay mixtures dispersed by methods A1 to A4 in order to verify the impact of clay addition on viscosity. As illustrated in Figure 5, the viscosity increases by up to four-times if compared to the neat resin A0, with $3 \%$ wt of nanoclay content. However, the A1 blend shows a non-Newtonian shear-thinning behaviour while blends A2 to A4 exhibit a nearly Newtonian behaviour similar to the neat resin A0. The non-Newtonian behaviour of mix A1 may be a direct consequence of the creation of links between the nanoparticles and the resin. It can be concluded from these results that only the dispersion technique A1 would be able to produce a well-dispersed and probably intercalated/exfoliated structure. An exfoliated structure would result in higher surface interaction due to the physical properties of the montmorillonite clay itself and intercalation due to the polymer diffusion into the galleries of the nanoclays [42-44]. Durán et al. [45] observed a similar behavior for montmorillonite suspensions under shear experiments, and Sinha [3] showed that the linear viscoelastic performance of the polymer chains are indeed altered by the addition of the nanoparticles in the composition. The dispersion method chosen requires the use of styrene as the dispersion media. Due to its low viscosity $(0.762 \mathrm{~m} \mathrm{~Pa} \cdot \mathrm{s})$ the styrene allows better movement of the particles. Adding the resin afterwards seals the internal structure and maintains the intercalated-exfoliated structure.

Figure 6 shows the results of shear viscosity tests carried out on the Envirez Q11500 UP bioresin charged with 3\% wt of Cloisite $30 \mathrm{~B}$ nanoclays dispersed with the A1 technique. In this analysis, successive shear tests were conducted to study the reorientation of the nanoclays platelets along the rotation axis. During the first rotation, the viscosity of the blends at a shear rate of $0.1 \mathrm{sec}^{-1}$ is $0.8 \mathrm{~Pa} \cdot \mathrm{s}$, reducing to $0.3 \mathrm{~Pa} \cdot \mathrm{s}$ for a shear rate of $100 \mathrm{sec}^{-1}$. This shear thinning behaviour is related to the reorientation of the nanoclays platelets around the rotational axis. When the test is held for one minute before starting the second rotation, the nanoclays tend to reorganize in their original random position. As a consequence, the viscosity at low shear rates during the second sweep is lower than for the first. This phenomena is also reproduced for the third shear rate sweep. However, for all three cases, the viscosity of the blends is the same for high shear rate of $100 \mathrm{sec}^{-1}$, showing that the same reorientation of nanoparticles appears after all three sweeps.

Figure 7 shows the initial viscosity at a constant shear rate of $0.1 \mathrm{~s}^{-1}$, for various types and percentage of Cloisite nanoclay dispersed in the bioresin Q11500. Generally, the viscosity increases with the nanoparticles content. It is notable 
TABLE 3: SCRIMP and RTM process parameters.

\begin{tabular}{lcccccc}
\hline & Part size $(\mathrm{mm})$ & $\begin{array}{c}\text { Fiber volume } \\
\text { content } V_{f}(\%)\end{array}$ & $\begin{array}{c}\text { Resin injection } \\
\text { pressure }(\mathrm{kPa})\end{array}$ & $\begin{array}{c}\text { Mold and preform } \\
\text { temperature }\left({ }^{\circ} \mathrm{C}\right)\end{array}$ & $\begin{array}{c}\text { Vacuum pressure } \\
(\mathrm{kPa})\end{array}$ & $\begin{array}{c}\text { Closing mold } \\
\text { pressure }(\text { tons })\end{array}$ \\
\hline RTM & $300 \times 100 \times 2.19$ & 40 & 138 & 80 & 70 & 10 \\
SCRIMP & $650 \times 300 \times 2.12$ & 41 & - & $\begin{array}{c}\text { Room } \\
\text { Temperature }\end{array}$ & $30-70$ & - \\
\hline
\end{tabular}

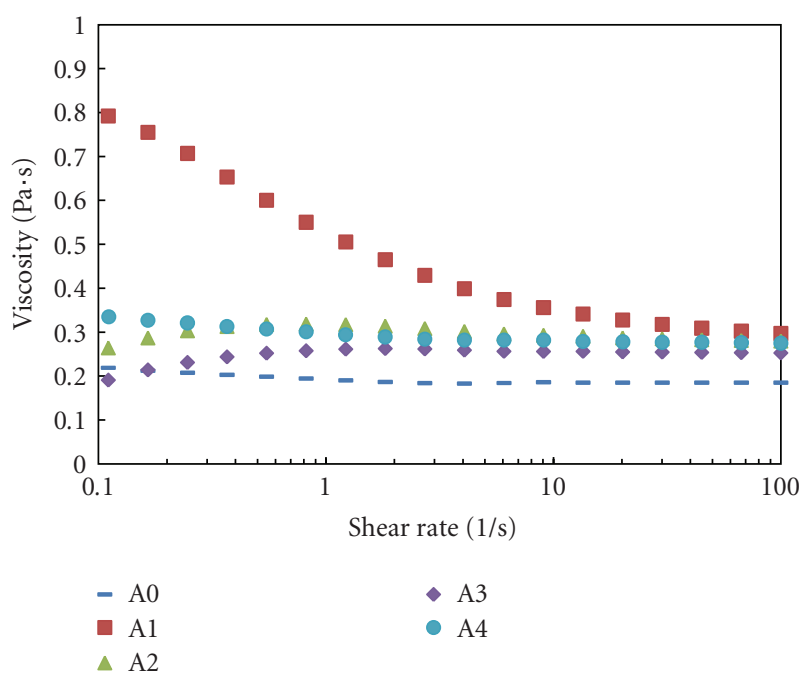

Figure 5: Shear viscosity sweep at $23^{\circ} \mathrm{C}$ for $3 \%$ wt C $30 \mathrm{~B}$ nanoclay dispersed in petroleum-based resin R937 by different methods.

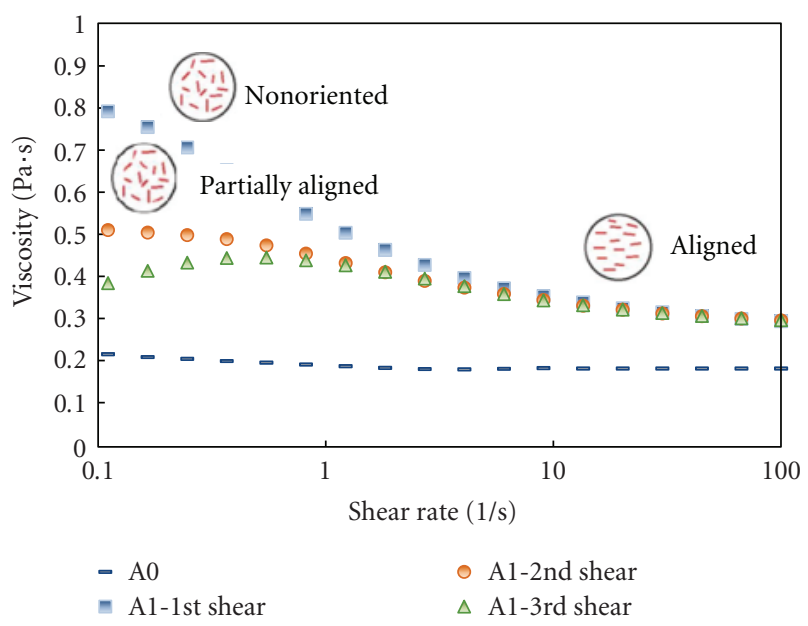

Figure 6: Successive shear viscosity sweeps at $23^{\circ} \mathrm{C}$ for $3 \%$ wt C30B nanoclay dispersed in petroleum-based resin R937 using the A1 mixing method.

that for the same amount of nanoclay, the viscosity is higher for $\mathrm{C} 15 \mathrm{~A}$ than for $\mathrm{C} 11 \mathrm{~B}$ and $\mathrm{C} 30 \mathrm{~B}$. This phenomenon can be related to the higher surface interaction between the nanoclays and the UP resin which leads to a possible better dispersion for C15A. This difference can be explained by the chemical treatment and d-spacing between nanoclay platelets. The latter can also have an impact on the capacity of the particle to exfoliate with sonication energy. As described in Table 1, even if particles $\mathrm{C} 15 \mathrm{~A}$ and $\mathrm{C} 11 \mathrm{~B}$ have almost

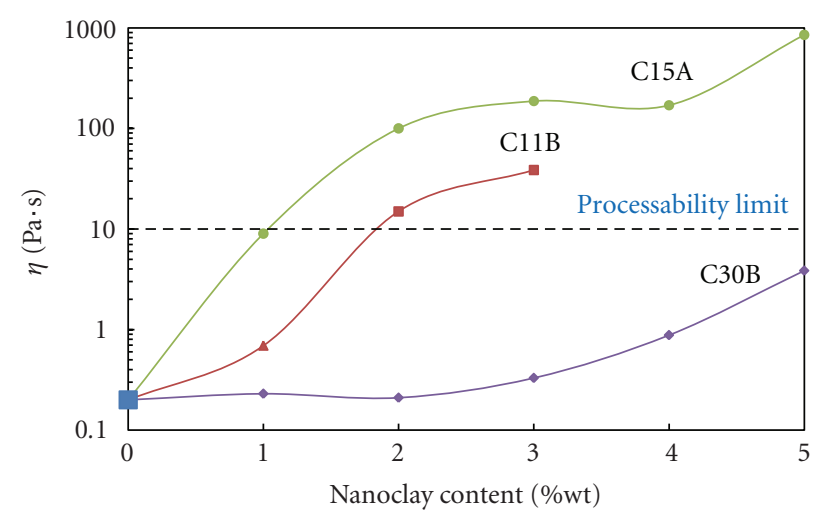

Neat bioresin

Figure 7: Viscosity at $23^{\circ} \mathrm{C}$ for various types of nanoclays and percentage. The dotted line indicates the maximum viscosity allowed for liquid composite molding.

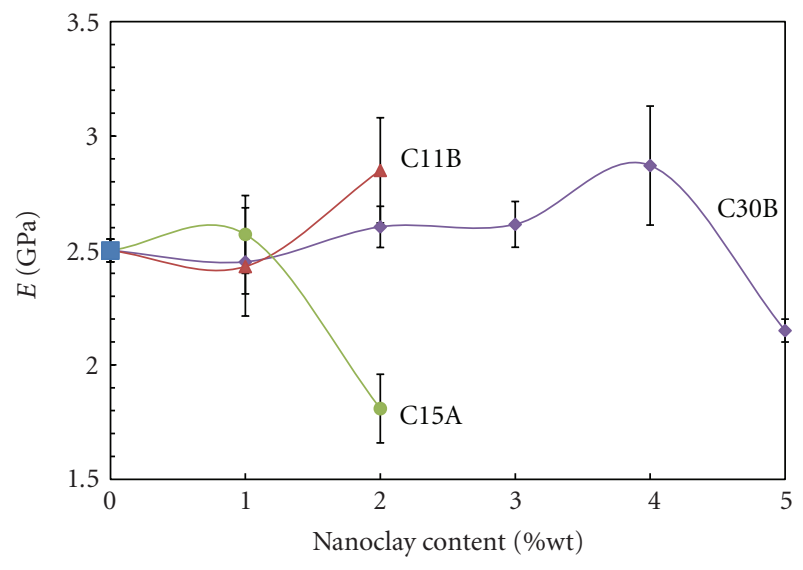

Neat bioresin

FIGURE 8: Flexural modulus of nanoclays reinforced polyester bioresin (matrix only).

the same chemical treatment, C15A has a higher d-spacing. This higher $\mathrm{d}$-spacing will facilitate the diffusion of the polymer macromolecules between the platelets resulting in higher surface interaction and higher viscosity. For C30B and $\mathrm{C} 11 \mathrm{~B}$, the d-spacing is similar, but their chemical treatment was different. This will affect the initial viscosity value, respectively, $0.28 \mathrm{~Pa} \cdot \mathrm{s}$ and $0.8 \mathrm{~Pa} \cdot \mathrm{s}$.

3.2. Processability Analysis. In LCM processes, the impregnation of the fibrous preform and time required to fill up the mold are intimately related to the viscosity of the resin. 


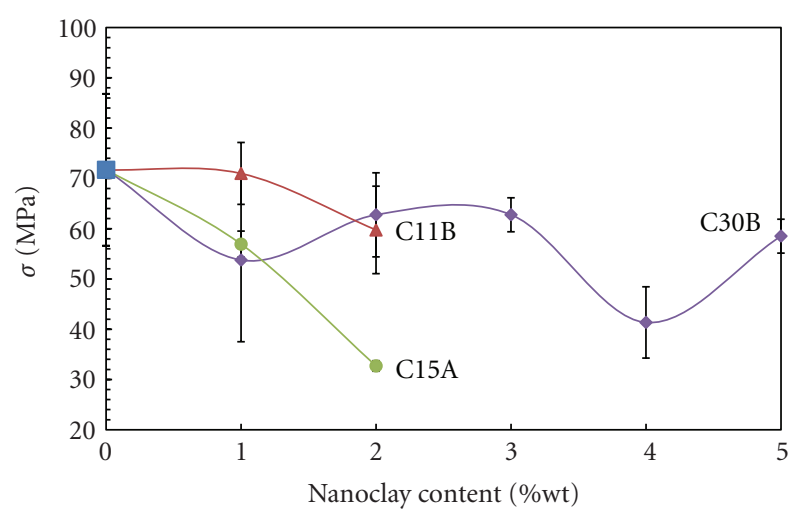

Neat bioresin

FIGURE 9: Ultimate strength of nanoclays reinforced polyester bioresin (matrix only).

These manufacturing processes are limited to low viscosities due to the very dense nature of typical porous media to be infiltrated (i.e., compacted fibers) and relatively low infusion pressures compared to injection molding of pure plastics. In practice, resin viscosity is limited to $1 \mathrm{~Pa} \cdot \mathrm{s}$ for SCRIMP process and $10 \mathrm{~Pa} \cdot \mathrm{s}$ for RTM. This processability limit of the nanocharged resin is illustrated in Figure 7 by the dotted line at $10 \mathrm{~Pa} \cdot \mathrm{s}$. These manufacturing requirements limit the application of nanoclays to $1 \%$ for $\mathrm{C} 15 \mathrm{~A}, 2 \%$ for $\mathrm{C} 11 \mathrm{~B}$, and $5 \%$ for C30B. These nanoclay concentrations are applied in this study for the manufacture of composite laminates with the nanocharged bioresin.

3.3. Mechanical Properties of Nanoclay Composites. In this work, different types and percentages of nanoclays were used to study their impact on mechanical properties of the composite laminate. The resulting flexural properties for $\mathrm{C} 11 \mathrm{~B}, \mathrm{C} 15 \mathrm{~A}$, and $\mathrm{C} 30 \mathrm{~B}$ nanocharges are shown in Figures 8 and 9. As illustrated in Figure 8, the addition of $1 \% \mathrm{wt}$ of nanoclays does not have an impact on flexural modulus. This is most probably due to the low interaction between nanoparticles dispersed in the matrix. However, significant increases are observed for contents above $2 \% \mathrm{wt}$.

The flexural modulus of the nanofilled resin samples decreases to $1.6 \mathrm{GPa}$ with the addition of $2 \% \mathrm{wt}$ of Cloisite $15 \mathrm{~A}$. This decrease in elastic properties is related to the very high viscosity of the mix (see Figure 7) and the limitations of the processability by the SCRIMP technique. For samples manufactured with Cloisite $11 \mathrm{~B}$ and $30 \mathrm{~B}$, an increase in elastic modulus is observed for 2 to $4 \%$ wt of nanoclays content. Dispersion of nanoparticles in the resin is limited to $2 \%$ for $\mathrm{C} 11 \mathrm{~B}$ and $5 \%$ for $\mathrm{C} 30 \mathrm{~B}$. In these cases, significant agglomerates were observed after dispersion, which have decreased the elastic response of the composite laminates. It can be concluded from Figure 8 that the elastic modulus of the nanocharged bioresin can be improved with the addition of $2 \%$ of Cloisite $11 \mathrm{~B}$ and 3 to $4 \%$ of C30B.

Figure 9 shows the resulting ultimate strengths of the nanocharged bioresin manufactured at different proportions of nanoclays. It was observed that for all samples, the ultimate

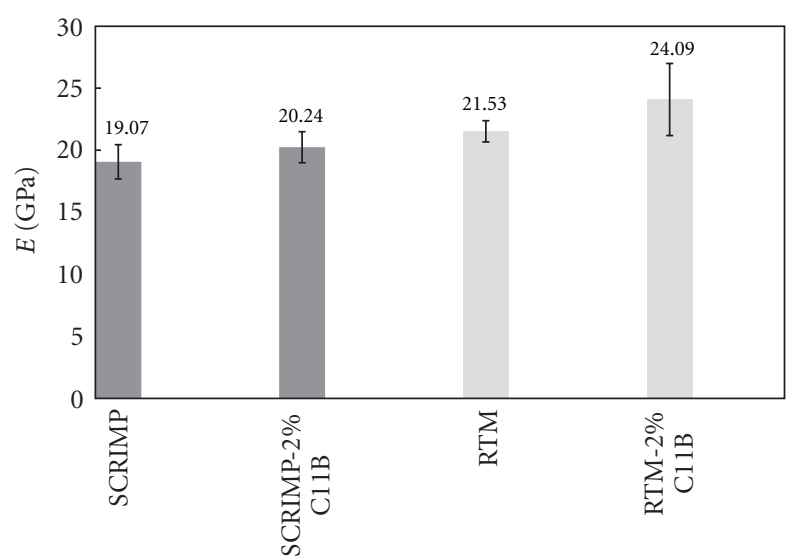

(a)

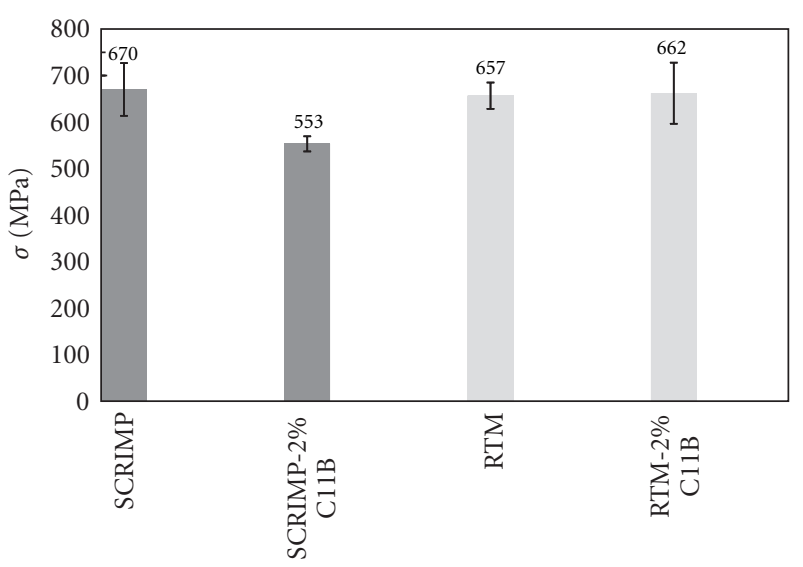

(b)

FIGURE 10: Mechanical properties of composite laminates made by RTM and SCRIMP processes: (a) flexural modulus, (b) utimate strength.

strength is lower than the neat resin, and the worst case is for $2 \%$ wt of C15A. This decrease in the ultimate strength is probably due to the fact that the nanoclays platelets are probably well dispersed but not exfoliated. Due to the relatively large amount of resin required to manufacture the composite plates, the ultrasonication technique used in this work may not guarantee full dispersion and exfoliation of the nanoclays. If agglomerates are present in the nanocharged resins, polymer chains will not diffuse between the clay platelets creating voids inside the agglomerate. This material discontinuity will initiate microcracking that decreases the ultimate strength of the composite laminate, which may explain the variability in the data for Cloisite 30B. It can also be concluded from Figures 8 and 9, that Cloisite 15 A is not appropriate to be used as reinforcement for the Q11500 bioresin. Moreover, both C11B and C30B, at 2 and $3 \% \mathrm{wt}$, respectively, are suitable as nanoreinforcements for composite laminates manufactured by SCRIMP and RTM processes. For the remainder of this study, which will focus on the manufacturing, the Cloisite $11 \mathrm{~B}$ was chosen at a concentration of $2 \%$ wt.

In order to study the feasibility of nanoreinforced composites, rectangular plates were injected using the processes 


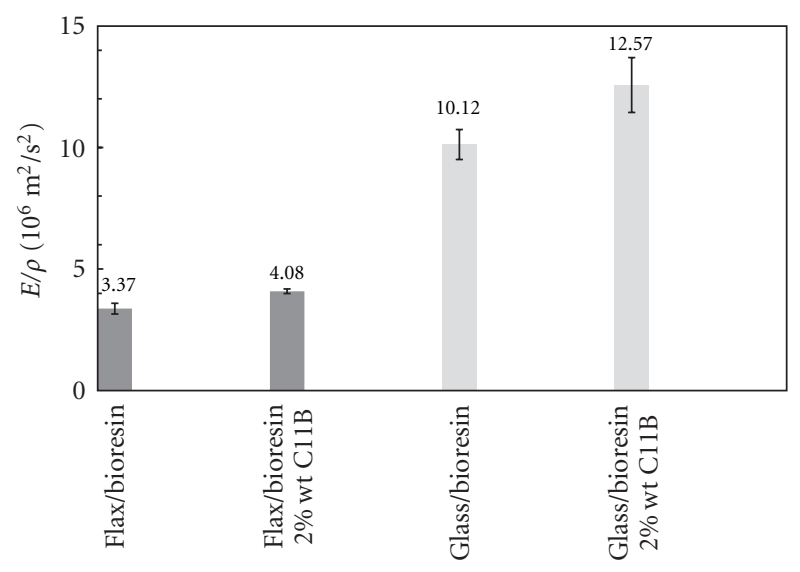

(a)

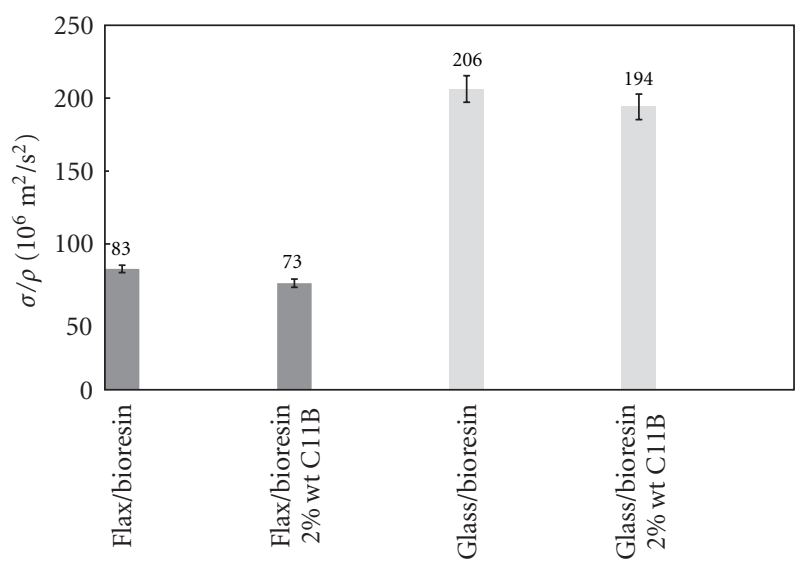

(b)

Figure 11: Mechanical properties of glass and flax reinforced nanoclays composite made by SCRIMP process: (a) specific flexural modulus (b) specific ultimate strength.

described above. These composite plates were manufactured using bidirectional glass fibers as described in Table 1. The Q11500 UP bioresin containing 8\% of soy oil was mixed with $2 \%$ of $\mathrm{C} 11 \mathrm{~B}$ nanoclays. Prior to RTM injection, the mold was heated to $80^{\circ} \mathrm{C}$ to reduce cycle time and improve impregnation of the fibers. Table 2 summarizes the parameters used for RTM processing. Figure 10 illustrates the resulting mechanical properties of the composite plates with pure resin, and with resin nanoreinforced with $2 \%$ wt of C11B. These experimental data show that the RTM process results in improved mechanical properties as compared to the SCRIMP process. This was due to the higher molding temperature which improves fibers impregnation, higher injection pressure, and rigid mold that ensure a constant thickness and thus, a constant fiber volume fraction.

The addition of $2 \%$ of nanoclay $\mathrm{C} 11 \mathrm{~B}$ provided an improvement of both the flexural modulus and ultimate strength for both processes. An improvement of $11 \%$ in flexural modulus results of RTM laminates whereas it was $6 \%$ for the SCRIMP laminates. No significant changes were observed in ultimate strength for both processes, taking into consideration the standard deviation. Even if this improvement of mechanical properties appears promising, it may be

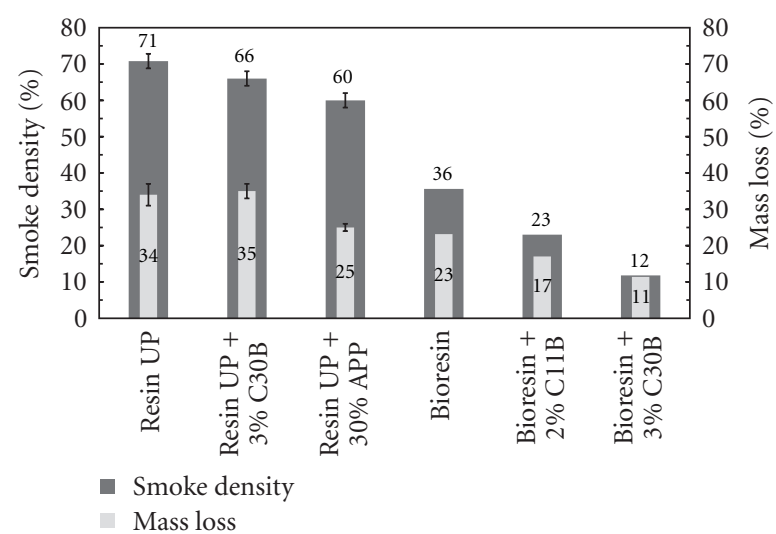

FIGURE 12: Results of the flammability tests carried out on various composite laminates made by SCRIMP process.

considered to be irrelevant due to the complexity of mixing the nanoparticles with the resin.

One of the purposes of this research was the manufacturing of green composite nanoreinforced with mineral particles. To do so, glass fibers were replaced by natural fibers and a green composite was made with soy-based resin injected with the SCRIMP process. The manufacturing conditions were the same as of the previous case, except that there were eight layers of $0^{\circ} / 90^{\circ}$ flax or glass fibers instead of six. Figure 11 shows the results of the mechanical tests carried out on the green composites. Using the law of mixtures, it was found that the specific properties $E / \rho$ and $\sigma / \rho$ of natural composites are much lower than those of the glass fiber composites at an equivalent fiber volume fraction of $50 \%$. This was identified as a limitation for the practical use of these green composites. The addition of $2 \% \mathrm{wt}$ of nanoclays C11B improved the flexural modulus of flax laminates by $18 \%$, which is in the same order of magnitude as for the glass laminates of Figure 10. However, the ultimate stress carried by the natural fiber composites was slightly reduced by the addition of nanoclays. These latter results would require further study to develop a better understanding of the underlying reasons.

\section{Flammability Results}

Flammability of composite parts is a major concern since the considerable amount of smoke and toxic fumes released during burning restrict their use in the transport and building applications. Additives such as ammonium polyphosphate (APP) are often used as flame retardants in replacement of more toxic additives used in the past. However, the addition of a significant amount of these particles decreases the mechanical properties of the resin. Thus, one of the aims of the present research was to study the use of nanoclays as a potential flame retardant.

To analyze the flame retardancy of nanoclay reinforced composites, glass fiber plates were produced by the SCRIMP process using the bioresin with different amounts of nanoclay. Figure 12 shows the resulting smoke density and mass 
loss of the six tested laminates. These measurements were carried out with a smoke density test facility modified to fit the ASTM D2843 standard. Six samples were tested in order to get a good reproductability within the results. The first part of the study was conducted using a petroleumbased UP resin, resulting in a smoke density of $71 \%$ and a loss of one-third of the mass after burning. Then the glass fibers/petroleum-based UP resin laminates were manufactured adding $30 \%$ of APP flame retardant or $3 \%$ wt C30B nanoclay particle. The smoke density of these samples was reduced to 60 and $66 \%$, respectively. The addition of $30 \%$ of APP resulted then in a diminution of $15 \%$ in the smoke density and $26 \%$ in the mass loss. The addition of $3 \%$ of nanoclays equals the improvement of the flame retardancy for these laminates.

In the second part of this study, the petroleum-based UP resin was replaced by the soy oil diluted resin Q11500. For the neat bioresin/glass fibers laminate, the smoke density was reduced to $36 \%$ and the mass loss to $23 \%$. This is an improvement of more than $50 \%$ of the results obtained with the petroleum-based resin. The addition of $2 \%$ of $\mathrm{C} 11 \mathrm{~B}$ nanoclays to this soy-based resin reduced the smoke density to $23 \%$ and the mass loss to $17 \%$ while the addition of $3 \% \mathrm{wt}$ C30B resulted in only $12 \%$ of smoke density and $11 \%$ of mass loss. These results clearly indicate the potential use of nanoclays as an effective, more environment friendly flame retardant for bio-composites. This difference between C11B and $\mathrm{C} 30 \mathrm{~B}$ can be explained by their chemical affinity to the soybean oil contained in the Q11500 resin.

\section{Concluding Remarks}

In this paper, rheology analyses were completed on different nanoclay mixtures dispersed in a styrene media. Experimental rheological and mechanical analyses have shown that the properties of the charged resin are directly dependent on the nanoclay content as well as on the chemical treatment used to functionalize the nanoclays. Two bidirectional reinforcements: glass and flax fibers, were used to manufacture parts using RTM and SCRIMP processes. Two types of resin: petroleum-based unsaturated polyester and soy oil-based resin were also investigated, with three types of nanoclays: Cloisite $11 \mathrm{~B}, 30 \mathrm{~B}$, and 15A. The choice of nanoparticles for manufacturing was restricted to the processability limit of the nanocharged resin of $10 \mathrm{~Pa} \cdot \mathrm{s}$. First, mechanical property evaluation showed that the elastic modulus of the nanofilled resin with only $2 \%$ of Cloisite $11 \mathrm{~B}$ increased by $14 \%$ : however, the ultimate stress decreases by $16 \%$. This type of nanoreinforcement was chosen for further manufacturing of laminates.

Composite plates manufactured with glass and flax fibers were mechanically tested showing an improvement of $6 \%$ with the SCRIMP process and 11\% for RTM when adding $2 \mathrm{wt} \%$ of nanoclays. The laminates made with natural fibers showed an increase of $18 \%$ of the elastic modulus. Finally, fire resistance of nanocomposites was evaluated with the smoke density tests. The addition of $3 \mathrm{wt} \%$ of nanoclays improved the flammability by up to $30 \%$ compared to the conventional composite, and the combination of nanoclay and bioresins doubled this value. Moreover, replacing current flame retardant, such as APP, by nanoclay particles is ecological and also reduces the impact of petroleum and chemical-based products. This study illustrates that the use of well-dispersed nanoclays in polyester resin brings a global improvement and is suitable for resin infusion process.

\author{
Abbreviations \\ GFC: $\quad$ Glass fibers composite \\ GF-NC: Glass fibers nanocomposite \\ GFBiores-C: Glass fibers bioresin composite \\ GFBiores-NC: Glass fibers bioresin nanocomposite \\ FFBiores-C: Flax fibers bioresin composite \\ FFBiores-NC: Flax fibers bioresin nanocomposite \\ UP resin: Unsaturated polyester resin \\ Phr: $\quad$ Parts per hundred \\ Wt: Weight percentage.
}

\section{Acknowledgments}

The authors acknowledge the support provided by the Chair of High Performance Composite (CCHP) and the Center for Applied Research on Polymers and Composites (CREPEC). The financial contribution of the Natural Sciences and Engineering Research Council of Canada (NSERC) is also greatly appreciated.

\section{References}

[1] S. Abend and G. Lagaly, "Sol-gel transitions of sodium montmorillonite dispersions," Applied Clay Science, vol. 16, no. 3-4, pp. 201-227, 2000.

[2] W.-F. Lee and Y.-T. Fu, "Effect of montmorillonite on the swelling behavior and drug-release behavior of nanocomposite hydrogels," Journal of Applied Polymer Science, vol. 89, no. 13, pp. 3652-3660, 2003.

[3] S. Sinha Ray and M. Okamoto, "Polymer/layered silicate nanocomposites: a review from preparation to processing," Progress in Polymer Science, vol. 28, no. 11, pp. 1539-1641, 2003.

[4] F. Gao, "Clay/polymer composites: the story," Materials Today, vol. 7, no. 11, pp. 50-55, 2004.

[5] L. A. Utracki, M. Sepehr, and E. Boccaleri, "Synthetic, layered nanoparticles for polymeric nanocomposites (PNCs)," Polymers for Advanced Technologies, vol. 18, no. 1, pp. 1-37, 2007.

[6] F. Laoutid, L. Bonnaud, M. Alexandre, J. M. Lopez-Cuesta, and P. Dubois, "New prospects in flame retardant polymer materials: from fundamentals to nanocomposites," Materials Science and Engineering R, vol. 63, no. 3, pp. 100-125, 2009.

[7] D. Dean, A. M. Obore, S. Richmond, and E. Nyairo, "Multiscale fiber-reinforced nanocomposites: synthesis, processing and properties," Composites Science and Technology, vol. 66, no. 13, pp. 2135-2142, 2006.

[8] J. Denault and B. Labrecque, "Groupe technologique sur les nanocomposites polymères-PNC-Tech," 2002, http://ww2 .imi.nrc.ca/francais/PDF/factsheets/pnc-tech.pdf.

[9] S. Nazare, B. K. Kandola, and A. R. Horrocks, "Flameretardant unsaturated polyester resin incorporating nanoclays," Polymers for Advanced Technologies, vol. 17, no. 4, pp. 294-303, 2006. 
[10] M. Bartholmai and B. Schartel, "Layered silicate polymer nanocomposites: new approach or illusion for fire retardancy? Investigations of the potentials and the tasks using a model system," Polymers for Advanced Technologies, vol. 15, pp. 355$364,2004$.

[11] M. Alexandre and P. Dubois, "Polymer-layered silicate nanocomposites: preparation, properties and uses of a new class of materials," Materials Science and Engineering R, vol. 28, no. 1, pp. 1-63, 2000.

[12] M. Haq, R. Burgueno, A. K. Mohanty, and M. Misra, "Processing techniques for bio-based unsaturated-polyester/clay nanocomposites: tensile properties, efficiency, and limits," Composites Part A: Applied Science and Manufacturing, vol. 40, no. 4, pp. 394-403, 2009.

[13] T. J. Pinnavaia and G. W. Beall, Polymer-8 Clay Nanocomposites, vol. 51, John Wiley \& Sons, Chichester, UK, 2000.

[14] D. Burgentzle, J. Duchet, J. F. Gerard, A. Jupin, and B. Fillon, "Solvent-based nanocomposite coatings: I. Dispersion of organophilic montmorillonite in organic solvents," Journal of Colloid and Interface Science, vol. 278, no. 1, pp. 26-39, 2004.

[15] I. Ortega, "Fabrication et caracterisation de nanocomposites a matrice epoxy," M.S. dissertation, Mechnanical Engineering, Ecole Polytechnique, Montreal, Canda, 2008.

[16] F. Hussain, D. Dean, A. Haque, and A. M. Shamsuzzoha, "S2 glass/vinylester polymer nanocomposites: manufacturing, structures, thermal and mechanical properties," Journal of Advanced Materials, vol. 37, no. 1, pp. 16-27, 2005.

[17] L. Y. Lin, J. H. Lee, C. E. Hong, G. H. Yoo, and S. G. Advani, "Preparation and characterization of layered silicate/glass fiber/epoxy hybrid nanocomposites via vacuumassisted resin transfer molding (VARTM)," Composites Science and Technology, vol. 66, no. 13, pp. 2116-2125, 2006.

[18] H. Miyagawa, A. K. Mohanty, R. Burgueno, L. T. Drzal, and M. Misra, "Novel biobased resins from blends of functionalized soybean oil and unsaturated polyester resin," Journal of Polymer Science Part B, vol. 45, no. 6, pp. 698-704, 2007.

[19] M. Haq, R. Burgueno, A. K. Mohanty, and M. Misra, "Biobased unsaturated polyester/layered silicate nanocomposites: Characterization and thermo-physical properties," Composites Part A: Applied Science and Manufacturing, vol. 40, no. 4, pp. 540-547, 2009.

[20] C. Weinong, S. Bo, L. Zengshe, and S. Erhan, "Compressive properties of epoxidized soybean oil/clay nanocomposites," International Journal of Plasticity, vol. 22, no. 8, pp. 1549-1568, 2006.

[21] Z. Liu, S. Z. Erhan, and J. Xu, "Preparation, characterization and mechanical properties of epoxidized soybean oil/clay nanocomposites," Polymer, vol. 46, no. 23, pp. 10119-10127, 2005.

[22] H. Uyama, M. Kuwabara, T. Tsujimoto, M. Nakano, A. Usuki, and S. Kobayashi, "Green nanocomposites from renewable resources: plant oil-clay hybrid materials," Chemistry of Materials, vol. 15, no. 13, pp. 2492-2494, 2003.

[23] R. Kozowski and M. Wadyka-Przybylak, "Flammability and fire resistance of composites reinforced by natural fibers," Polymers for Advanced Technologies, vol. 19, no. 6, pp. 446-453, 2008.

[24] N. R. C. o. Canada, "From fiber glass to biofibres," 2010, http:// www.nrc-cnrc.gc.ca/eng/dimensions/issue3/flax.html.

[25] P. J. Roe and M. P. Ansell, "Jute-reinforced polyester composites," Journal of Materials Science, vol. 20, no. 11, pp. 40154020, 1985.

[26] M. K. Sridhar, G. Basavarappa, S. G. Kasturi, and N. Balasubramanian, "Mechanical properties of jute-polyester comp- osites," Indian Journal of Technology, vol. 22, no. 6, pp. 213215, 1984.

[27] A. N. Shah and S. C. Lakkad, "Mechanical properties of jutereinforced plastics," Fibre Science and Technology, vol. 15, no. 1, pp. 41-46, 1981.

[28] E. T. N. Bisanda and M. P. Ansell, "The effect of silane treatment on the mechanical and physical properties of sisalepoxy composites," Composites Science and Technology, vol. 41, no. 2, pp. 165-178, 1991.

[29] S. V. Prasad, C. Pavithran, and P. K. Rohatgi, "Alkali treatment of coir fibres for coir-polyester composites," Journal of Materials Science, vol. 18, no. 5, pp. 1443-1454, 1983.

[30] W. D. Brouwer, "Natural fibre composites in structural components: alternative applications for Sisal?" 2010, http:// www.fao.org/docrep/004/y1873e/y1873e0a.htm.

[31] S. Horold, "Phosphorus flame retardants in thermoset resins," Polymer Degradation and Stability, vol. 64, no. 3, pp. 427-431, 1999.

[32] S. V. Levchik, "Halogen-free approach in fire retardancy of thermoplastic polyesters," Recent Advances in Flame Retardancy of Polymers, vol. 13, pp. 296-314, 2002.

[33] A. H. B. Kandola and D. Price, "Nanocomposites," in Fire Retardant Materials, chapter 6, Woodhead Publishing, Cambridge, UK, 2001.

[34] J. W. Gilman, C. L. Jackson, A. B. Morgan et al., "Flammability properties of polymer - Layered-silicate nanocomposites. Polypropylene and polystyrene nanocomposites," Chemistry of Materials, vol. 12, no. 7, pp. 1866-1873, 2000.

[35] J. W. Gilman, "Flammability and thermal stability studies of polymer layered-silicate (clay) nanocomposites," Applied Clay Science, vol. 15, no. 1-2, pp. 31-49, 1999.

[36] J. Gilman, T. Kashiwagi, A. Morgan et al., Flammability of polymer clay nanocomposites consortium: year one annual report, 2000.

[37] C. Wilkie, "Recent advanced in fire retardancy of polymerclay nanocomposite," in Recent Advances in Flame Retardancy of Polymers , vol. 13, pp. 206-217, Business Communications Company, Norwalk, Calif, USA, 2002.

[38] Q. Govignon, S. Bickerton, J. Morris, and P. A. Kelly, "Full field monitoring of the resin flow and laminate properties during the resin infusion process," Composites Part A: Applied Science and Manufacturing, vol. 39, no. 9, pp. 1412-1426, 2008.

[39] J. S. Leclerc and E. Ruiz, "Porosity reduction using optimized flow velocity in Resin Transfer Molding," Composites Part A: Applied Science and Manufacturing, vol. 39, no. 12, pp. 18591868, 2008.

[40] R. Wagener and T. J. G. Reisinger, "A rheological method to compare the degree of exfoliation of nanocomposites," Polymer, vol. 44, no. 24, pp. 7513-7518, 2003.

[41] R. Krishnamoorti, J. Ren, and A. S. Silva, "Shear response of layered silicate nanocomposites," Journal of Chemical Physics, vol. 114, no. 11, pp. 4968-4973, 2001.

[42] J. C. Pierre, C. R. D. K. Daniel, and P. C. Raj, Rheology of Polymeric Systems: Principles and Applications, Hanser Publishers, New York, NY, USA, 1st edition, 1997.

[43] T. Phillips, "The physics of whipped cream," 2008, http://science.nasa.gov/science-news/science-at-nasa/2008/25apr_cvx2.

[44] F. A. Morrison, Understanding Rheology, Oxford University Press, Nwe York, NY, USA, 2001.

[45] J. D. G. Durán, M. M. Ramos-Tejada, F. J. Arroyo, and F. González-Caballero, "Rheological and electrokinetic properties of sodium montmorillonite suspensions: I. Rheological properties and interparticle energy of interaction," Journal of Colloid and Interface Science, vol. 229, pp. 107-117, 2000. 

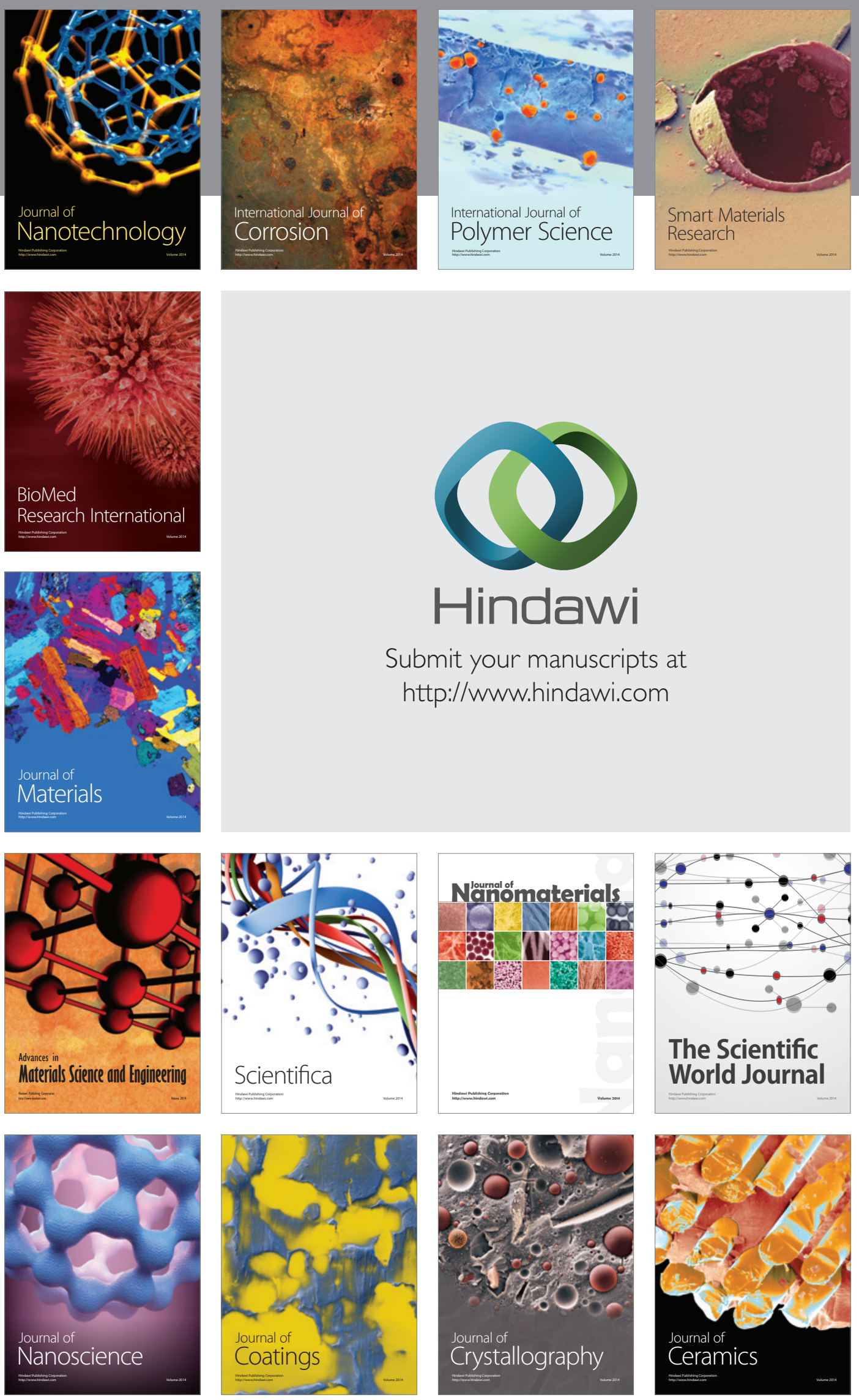

The Scientific World Journal

Submit your manuscripts at

http://www.hindawi.com

\section{World Journal}

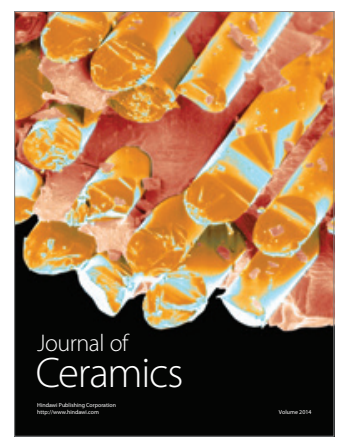

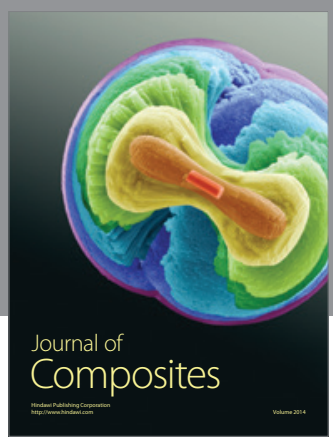
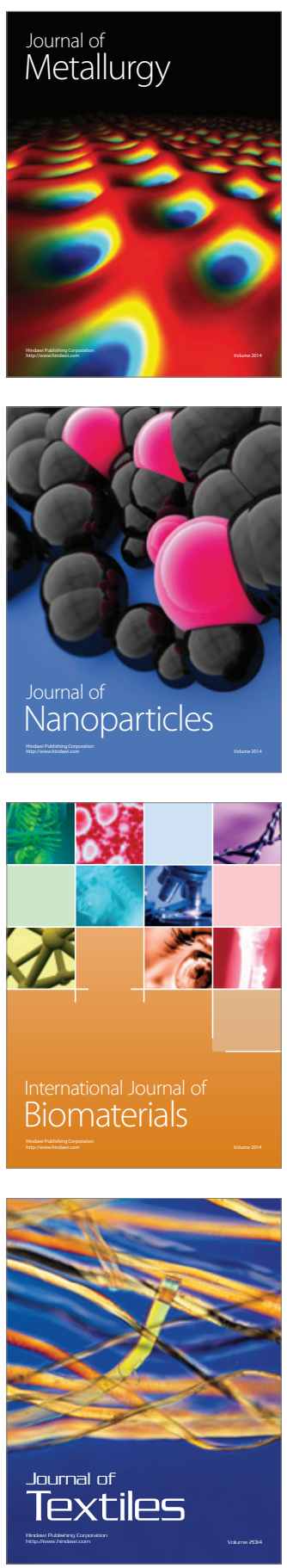